\title{
A Study on Vaginal Vault Cytology in Post Hysterectomy Patients with Possible Histopathological Correlation
}

\author{
Bodepudi Madhavi* and Lakshmi Manasa Perubhotla
}

Associate Professor, Pathology Department, Mamata Academy of Medical Sciences, Bachupally, Hyderabad, Telangana 500090, India Assistant Professor, Pathology Department, Mediciti Institute of Medical Sciences, Ghanpur, Medchal Mandal, Telangana 501401, India

DOI: $10.36348 /$ sjpm.2020.v05i10.002 $\quad$ | Received: 05.10.2020 | Accepted: 17.10 .2020 | Published: 23.10 .2020

*Corresponding author: Bodepudi Madhavi

\section{Abstract}

A total of 223 pap tests done on women who attended the outpatient ward for follow-up visits after posthystrectomy for malignant and benign indications between the years 2015 to till date in Mamata Medical College, Khammam and Mamata academy of medical sciences, Bachupally Hyderabad. Each woman under investigation had a clinical history, gynecological examination and a sample collected from the vaginal vault by using cytobrush or Ayres's spatula for preparing the Pap smear in the pathology department to study the vaginal vault cytology. A vaginal biopsy was also taken in possible cases for histopathology. Aims and objectives: Early detection of invasive and pre-invasive lesions in the vaginal vault in post hysterectomy patients by using Pap test as a Primary screening procedure. To determine the use and effectiveness of Pap smears in detecting Recurrent and primary malignant lesions on vaginal vault samples in posthysterectomy patients.

Keywords: Pap smear; Ayre's spatula, cytobrush, vaginal vault cytology.

Copyright @ 2020: This is an open-access article distributed under the terms of the Creative Commons Attribution license which permits unrestricted use, distribution, and reproduction in any medium for non-commercial use (NonCommercial, or CC-BY-NC) provided the original author and sources are credited.

\section{INTRODUCTION}

This prospective study is mainly aimed at identifying the atypical and malignant lesions in post hysterectomy patients by doing pap tests on specimens collected from the vaginal vault in the gynecology department by using the cytobrush or Ayres's spatula. The main aim of post-treatment surveillance in post hysterectomy patients is to improve the survival through early detection of recurrent tumors. High-grade cervical intraepithelial neoplasia (CIN), prior to or at the time of total hysterectomy, is a known risk factor for the development of secondary VAIN, with reported recurrence rates of $0.9-7.4 \%$ [1]. The majority of hysterectomies were performed for noncancerous conditions, including leiomyomas, menstrual disorders and endometriosis [2]. Rate of hysterectomies done for benign disease was 4.81 per 1,000 women-years [3]. Abnormal cytology is found in less than 2 per cent of vaginal cuff smears after hysterectomy for benign disease [4]. The highest incidence of VAIN is found in the first 2 years after hysterectomy, after that incidence falls to that of the general pre-hysterectomy population $[4,5]$. The proportion of hysterectomies performed for cancer or precancerous lesions has been reported to range from 6 to $10 \%[5,8]$. The cytopathologic examination is a one of the valuable method to detect an early recurrence of malignancy or new primary carcinoma during the follow-up of patients after the treatment of a different cancer[5,6].Hysterectomy may not be considered as a definitive therapy for CIN2+ because the incidence rate of subsequent VAIN2+ is as high as $7.4 \% .{ }^{[1]}$ By using cytobrush, and or Auer's spatula adequate sample is obtained for the Pap smear preparation and for subsequent cytological evaluation [7].

\section{MATERIAL AND METHODS}

This is a prospective study done from 2015 to till date on 223 post hysterectomy patients visiting gynecology department in Mamata medical college Khammam and Mamata Academy of medical sciences Bachupally on routine basis and also for the follow-up in patients who underwent hysterectomy with CIN-II, CIN-III and with invasive squamous cell cancer patients. This study is aimed at identifying the invasive and pre-invasive lesions in the vaginal vault by obtaining vaginal vault specimen collection by using Cytobrush and Ayres's spatula in the Gynecological department followed by making smears by using Pap stain in the Pathology department for cytological evaluation. Smear preparation was made according to standard pathological operative procedures. Criteria of 
adequacy for vaginal vault cytology consisted in the evaluation of adequate cellularity of squamous type. Vaginal biopsy was suggested for atypical and malignant lesions.

Total no of hysterectomies done in the study period were 223. The median patient age was 45 years (range 35 to 70 years) (table 1). Out of 223 patients $77.5 \%$ of the patients were from rural area (table 2). Hysterectomy done on 191 patients $(85 \%)$ secondary to benign indications (table 3 ), and on 31 patients $(15 \%)$ hysterectomy done for atypical and malignant lesions (table 4).

Table-1 and Graph1: Age wise distribution

\begin{tabular}{|c|c|c|c|}
\hline S. No. & $\begin{array}{c}\text { Age (in } \\
\text { years) }\end{array}$ & $\begin{array}{c}\text { Number of } \\
\text { patients }\end{array}$ & $\begin{array}{c}\text { Percentage } \\
\text { frequency }\end{array}$ \\
\hline 1. & $25-35$ & 21 & 9.4 \\
\hline 2. & $36-45$ & 61 & 27.3 \\
\hline 3. & $46-55$ & 57 & 25.5 \\
\hline 4. & $56-65$ & 49 & 21.9 \\
\hline 5. & $66-75$ & 29 & 13.0 \\
\hline 6. & $76-80$ & 06 & 2.9 \\
\hline TOTAL & & 223 & \\
\hline
\end{tabular}

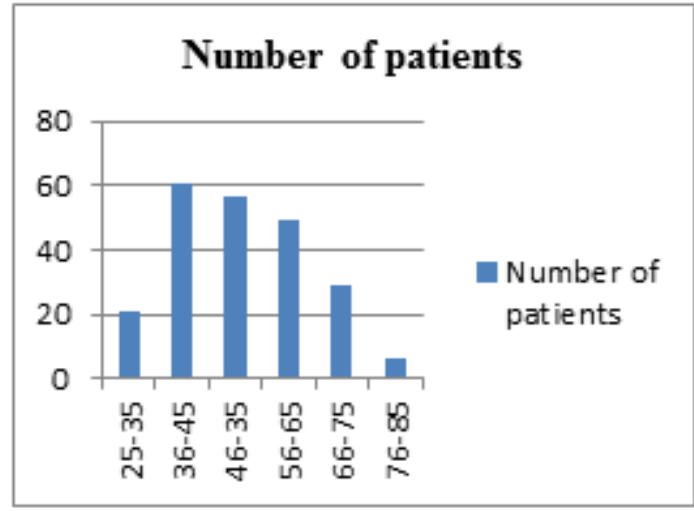

Table-II and Pie Chart I- Region wise distribution

\begin{tabular}{|c|c|c|c|}
\hline $\begin{array}{c}\text { S. } \\
\text { No. }\end{array}$ & Area & $\begin{array}{c}\text { Number of } \\
\text { patients }\end{array}$ & Percentage \\
\hline 1. & Rural & $\mathbf{1 7 3}$ & $\mathbf{7 7 . 5 \%}$ \\
\hline 2. & Urban & $\mathbf{5 0}$ & $\mathbf{2 2 . 5 \%}$ \\
\hline & TOTAL & $\mathbf{2 2 3}$ & $\mathbf{1 0 0 \%}$ \\
\hline
\end{tabular}

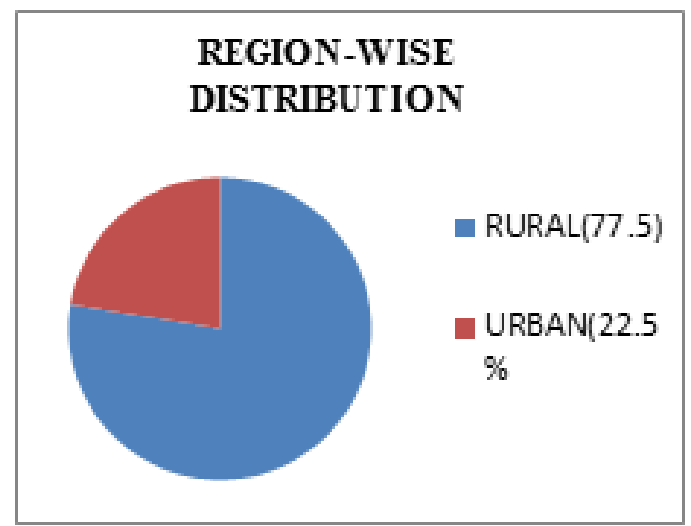

Table-III and Pie Chart II: Benign causes of Hysterectomy

\begin{tabular}{|c|c|c|c|}
\hline S. No & $\begin{array}{c}\text { Hysterectomy- } \\
\text { Benign cases }\end{array}$ & $\begin{array}{c}\text { No. Of } \\
\text { Patients }\end{array}$ & Percentage \\
\hline 1. & $\begin{array}{c}\text { Dysfunctional } \\
\text { uterine bleeding }\end{array}$ & 35 & 18.3 \\
\hline 2. & Fibroid Uterus & 33 & 17.2 \\
\hline 3. & $\begin{array}{c}\text { Post-menopausal } \\
\text { bleeding }\end{array}$ & 47 & 24.6 \\
\hline 4. & $\begin{array}{c}\text { Abnormal uterine } \\
\text { bleeding }\end{array}$ & 25 & 12.5 \\
\hline 5. & Chronic PID & 11 & 5.75 \\
\hline 6. & Cervical polyp & 5 & 2.61 \\
\hline 7. & UV prolapse & 23 & 12.0 \\
\hline 8. & Adenomyosis & 7 & 3.66 \\
\hline 9. & Ovarian cyst & 11 & 5.75 \\
\hline 10. & Puerperal sepsis & 2 & 1.04 \\
\hline
\end{tabular}

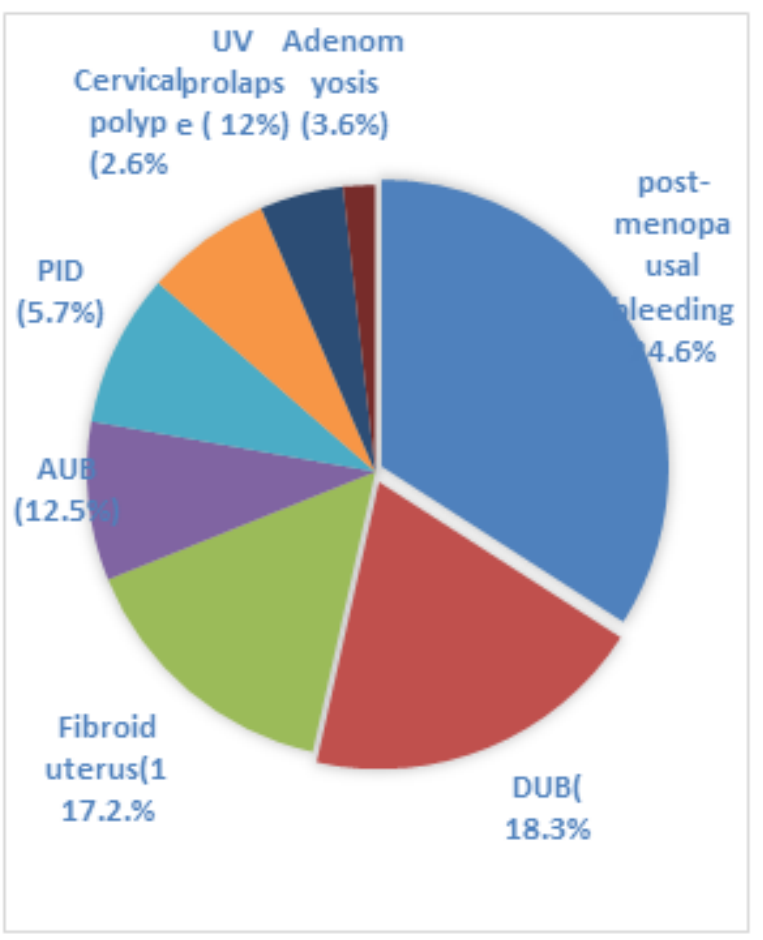

\section{RESULTS}

On follow-up visits in Pap smear cytology reports glandular cells were found in $39(13 \%)$ of the 223 vaginal smears. The glandular cells were 
categorized into three groups: (1) squamous metaplastic-like cells; (2) columnar endocervical-like cells; and (3) small round cuboidal cells. Group 1 type squamous metaplastic cells were seen in $76 \%$ cases followed by columnar endocervical and cuboidal cells of the smears (figure 1 and 2). In $9 \%$ of the smears combination of two or three groups were seen. The presence of glandular cells showed a strong association with inflammation/repair as a background finding in the smears. Mucinous endocervical columnar-like cells were seen in $9 \%$ of the cases, glandular cells not resembling endocervical cells in 7\%, and a combination of the former two categories in 8\%cases. Atrophic glandular cells of undetermined significance in $4 \%$ (figure 3 ) cases. In $2 \%$ smears therapy related changes are seen (figure 4)

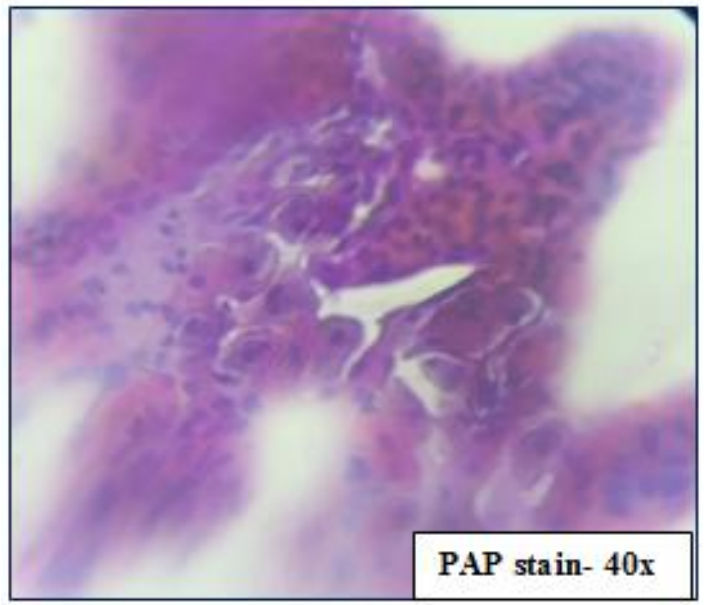

Fig-1: Vaginal vault smears showing Atrophic glandular cells

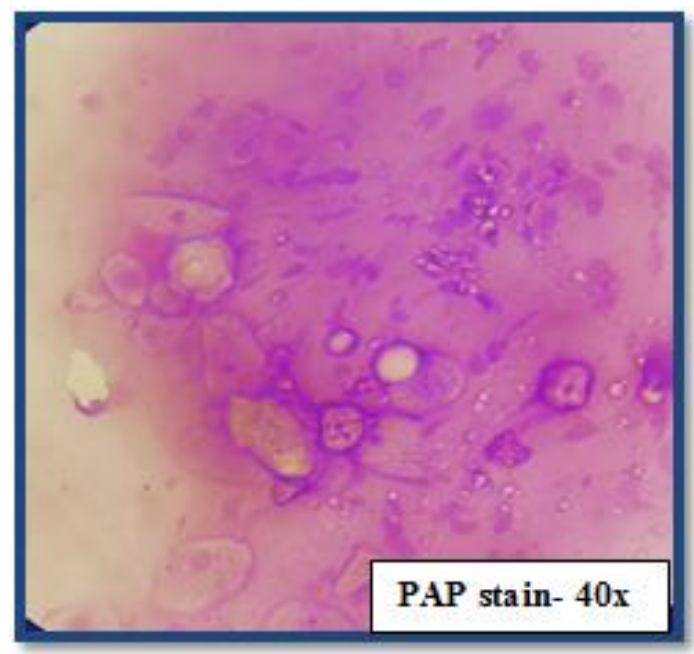

Fig-2: Vaginal vault smears showing Atrophic glandular cells

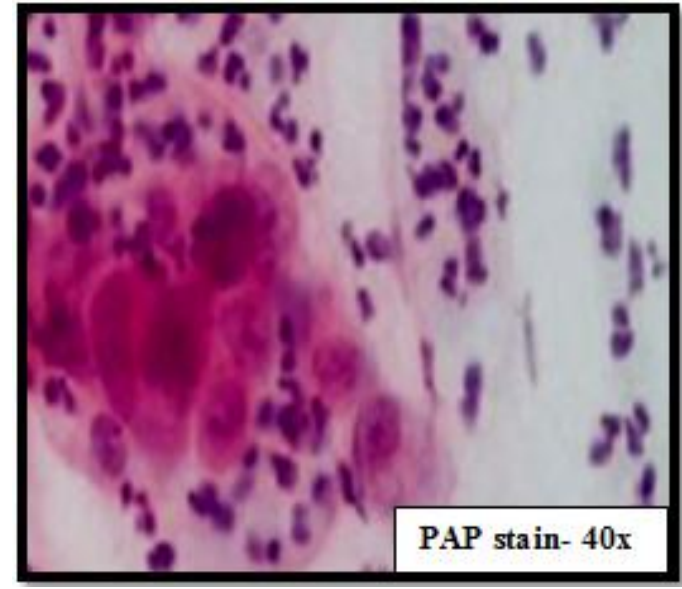

Fig-3: Atrophic glandular cells of undetermined Significance

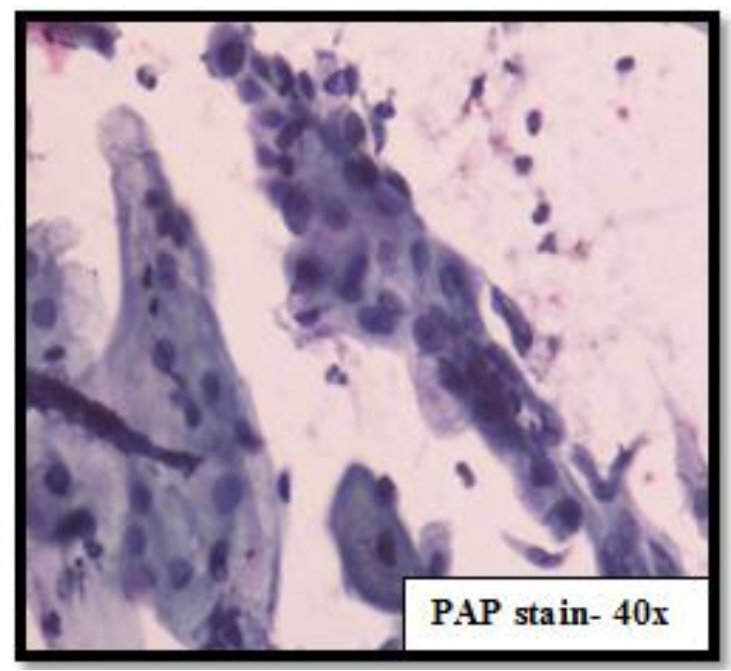

Fig-4: Therapy Related Changes- Inflammation keratinization and Anisonucleosis

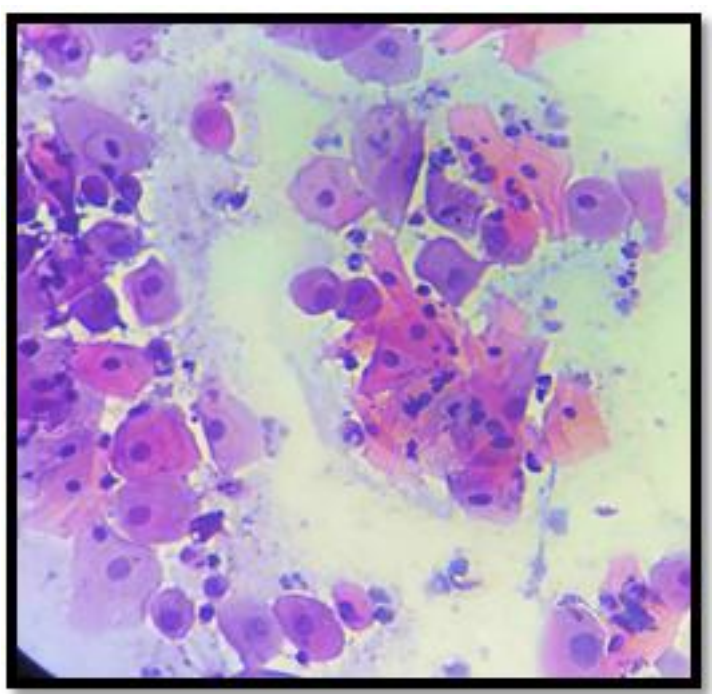

Fig-5: Vaginal intraepithelial lesion 1 


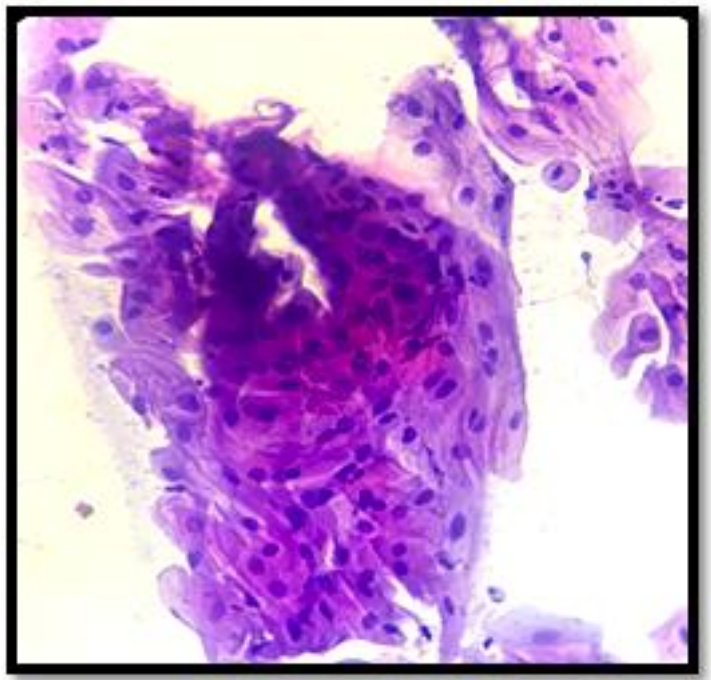

Fig-6: Vaginal intraepithelial lesion 11

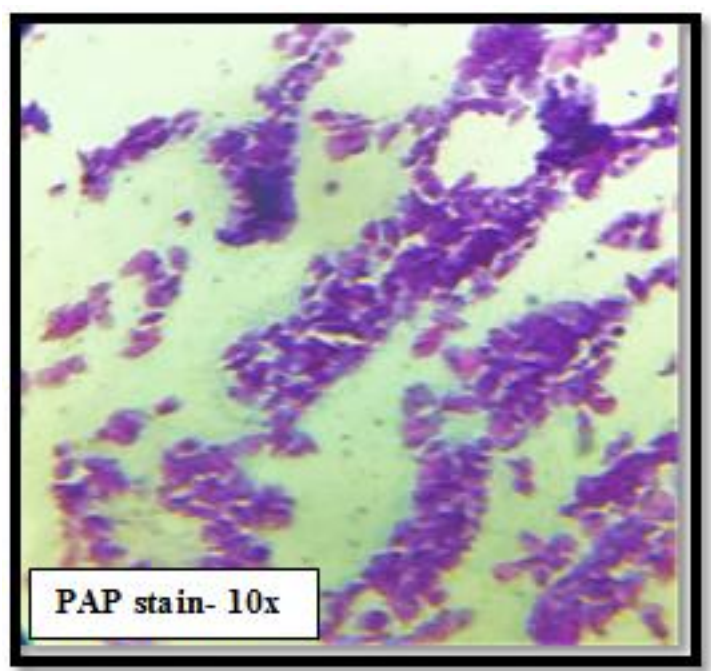

Fig-7: Vaginal cytology- metastatic - vaginal intraepithelial malignant lesion

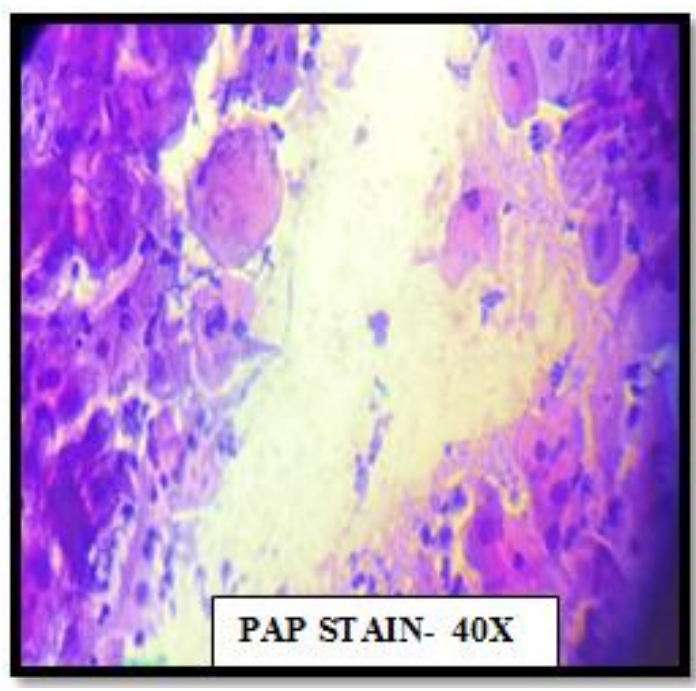

Fig-8: Vaginal cytology- metastatic - vaginal intraepithelial malignant lesion

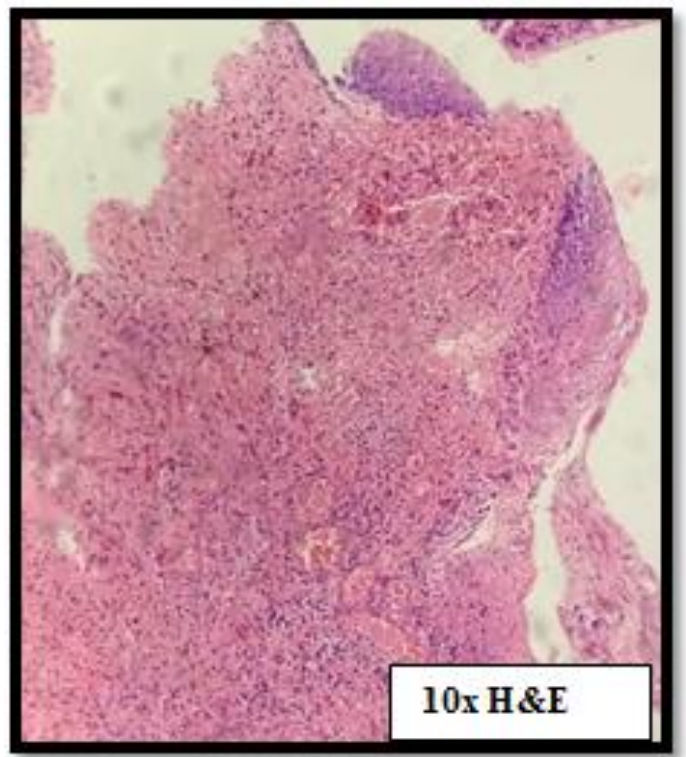

Fig-9: vaginal biopsy- metastatic - vaginal intra-epithelial

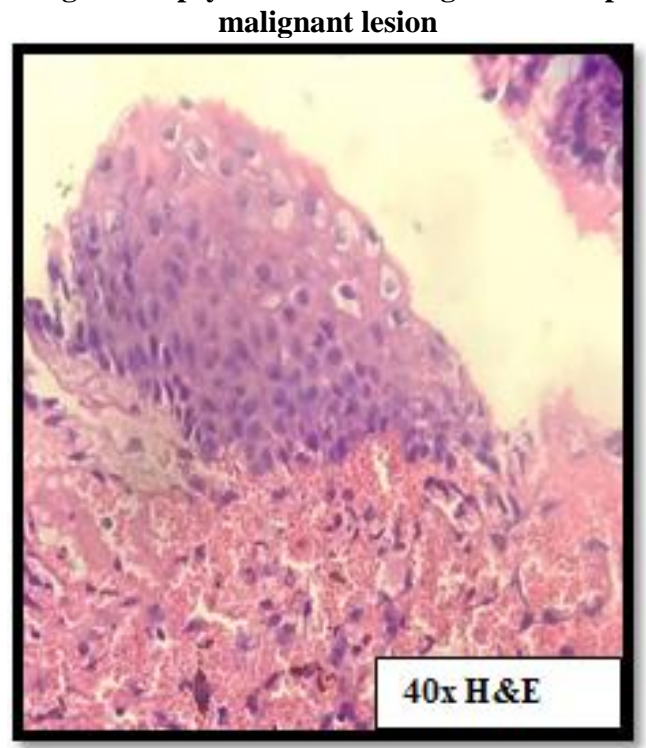

Fig-10: Vaginal biopsy- metastatic - vaginal intraepithelial malignant lesion

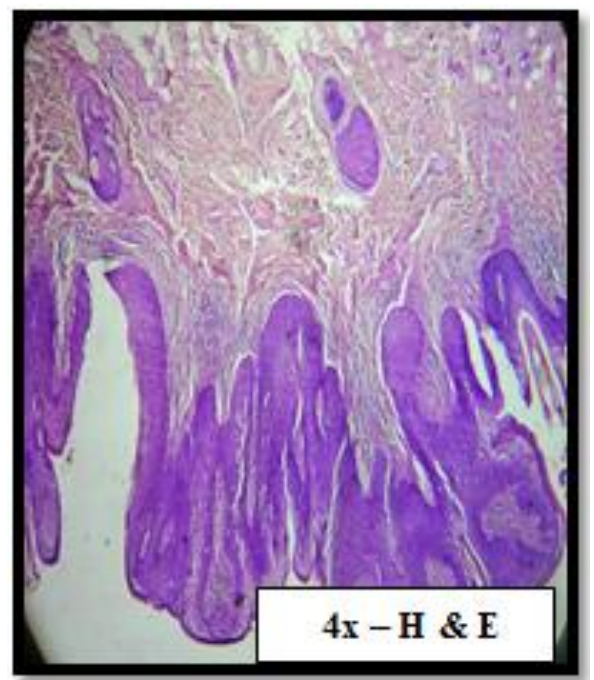

Fig-11: Bowen's Disease of Vulva 


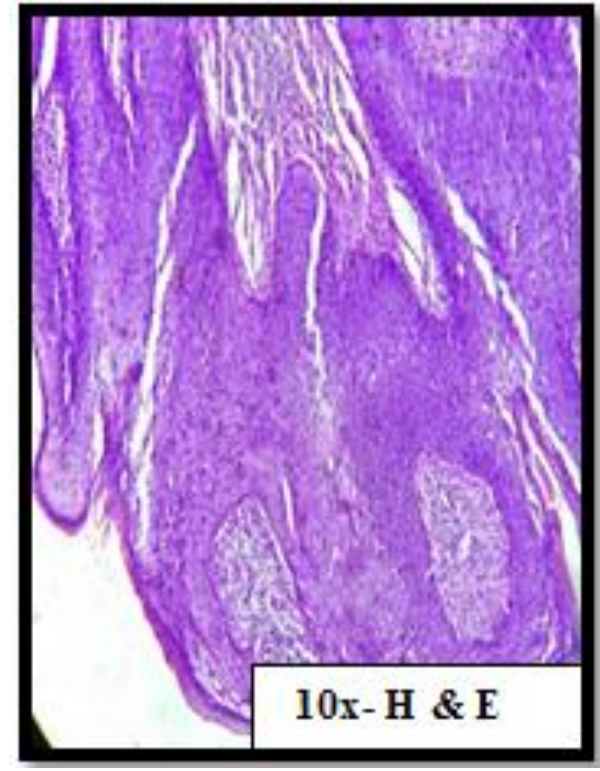

Fig-12: Bowen's Disease of Vulva

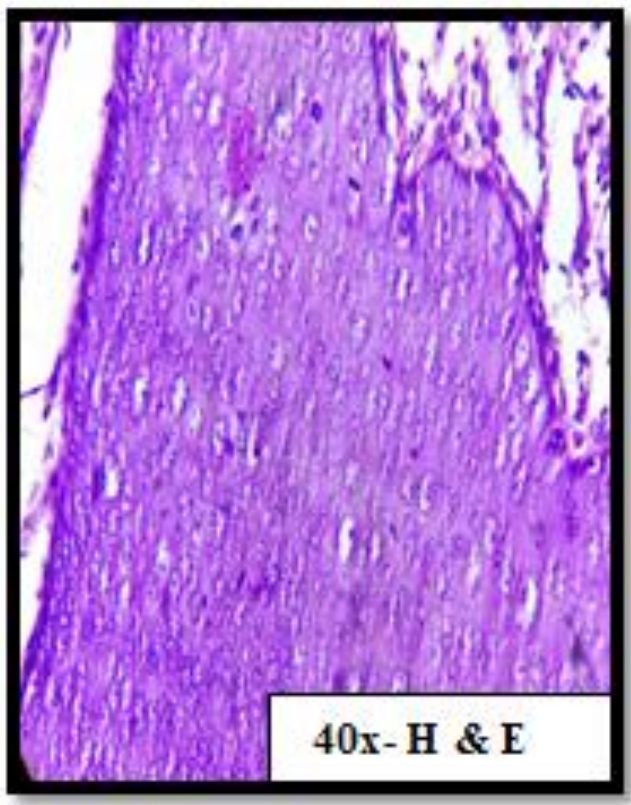

Fig-13: Bowen's Disease of Vulva

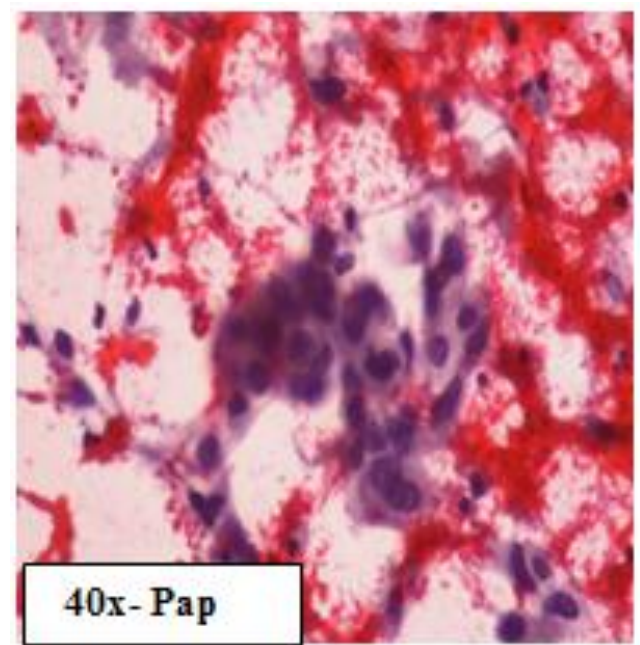

Fig-14: Vault Cytology Cyto and Histopathological correlation of Metastatic Squamous cell carcinoma

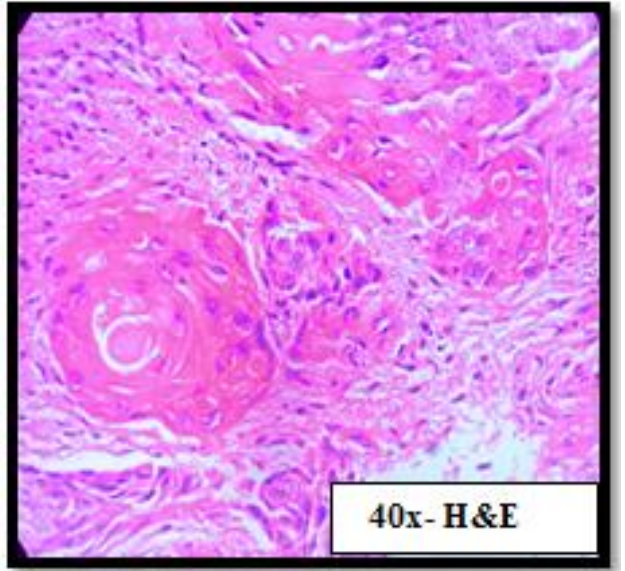

Fig-15: Vaginal Vault Biopsy Cyto and Histopathological correlation of Metastatic Squamous cell carcinoma

Hysterectomy secondary to benign indications ( $\mathrm{n}=199) 2.5 \%$ (5cases) of women had an abnormal smear, $0.05 \%$ (1case) and was correlated with biopsy shows one precancerous condition that is Bowen's disease and no cancers were identified (figure 8, 9\&10).

Hysterectomy secondary to CIN II: $62.5 \%$ (15cases out of 24 cases) 2 cases $(16.6 \%)$ had an abnormal vault smear, and 1 case $(8.3 \%)$ had an abnormal biopsy with atypical glandular cells of undetermined significance and no cancers were detected.

Hysterectomy secondary to CIN III (8 cases out of 24 cases) 4 cases $(33.2 \%)$ of women had an abnormal smear, and were correlated with biopsy findings of vaginal carcinoma in situ in 3 cases and case of Bowen's disease of vulva.

Hysterectomy done secondary to squamous cell carcinoma in 1 case and one intra epithelial vaginal cancer of squamous cell type was detected in vaginal vault cytology and was correlated with biopsy findings. 


\begin{tabular}{|l|l|l|}
\hline Indication of Hysterectomy & $\begin{array}{l}\text { Cytology Report on follow- } \\
\text { up vault Pap smear }\end{array}$ & Biopsy Report from vaginal vault \\
\hline $\begin{array}{l}\text { Benign causes of Hysterectomy } \\
(199)\end{array}$ & $\begin{array}{l}5 \text { cases (2.5\%) show atypical } \\
\text { glandular cells }\end{array}$ & $\begin{array}{l}\text { 1case (0.05\%) show atypical lesions with } \\
\text { reactive changes but no cancers. }\end{array}$ \\
\hline $\begin{array}{l}\text { Hysterectomy done in patients } \\
\text { with CIN11 (15 cases) 62.5\% out } \\
\text { of 24 cases }\end{array}$ & $\begin{array}{l}\text { 2 cases (16.6\%) show } \\
\text { abnormal cytological } \\
\text { features-VAIN 1 }\end{array}$ & $\begin{array}{l}\text { case }(8.3 \%) \text { correlated with atypical } \\
\text { lesions of reactive type and no cancer. }\end{array}$ \\
\hline $\begin{array}{l}\text { CIN III 8 cases out of 24 cases } \\
\text { (33.3\% cases) }\end{array}$ & $\begin{array}{l}\text { 4 cases (33.2\%) had } \\
\text { abnormal smear with } \\
\text { metastatic lesions VAIN I \& } \\
\text { VAIN II (Figure 6) }\end{array}$ & $\begin{array}{l}\text { 4 cases had an abnormal biopsy (33.2\%) } \\
\text { with vaginal carcinoma in situ in 3 cases } \\
\text { and in case Bowen's disease of vulva. } \\
\text { (7,8,9,10, 11, 12, 13) }\end{array}$ \\
\hline $\begin{array}{l}\text { Hysterectomy done secondary to } \\
\text { squamous cell carcinoma in 1 } \\
\text { case. (4.16\%) }\end{array}$ & $\begin{array}{l}\text { Metastatic squamous cell } \\
\text { carcinoma (4.16\%) } \\
\text { (figure 14) }\end{array}$ & $\begin{array}{l}\text { Metastatic Invasive vaginal (4.16\%) } \\
\text { cancer of squamous cell type. } \\
\text { (figure 15) }\end{array}$ \\
\hline
\end{tabular}

\{Comparison study: Systematic review: Vaginal vault smears after hysterectomy for reasons other than malignancy: a systematic review of the literature

My study: Subsequent to benign indications ( $n=223$ ), 2.5\% (5 cases) of women had an abnormal smear, $0.04 \%$ (1 case) had and there was no cancer on biopsy

Subsequent to CIN I or II (15 cases): (2 cases) (16.6\% had an abnormal vault smear, (1case) and 8.3\% with and on biopsy no cancers were detected.

Subsequent to CIN III, ( 4 cases) $33.2 \%$ of women had an abnormal smear with metastatic lesions ( VAIN 1 \&2) , $24.9 \%$ cases with metastatic lesions of VAIN 1\& VAIN11 on biopsy and 1 premalignant lesion( $8.3 \%$ ) Bowen's disease of vulva. vaginal cancer $(0.03 \%)$ was detected.

Subsequent to Squamous cell carcinoma of cervix ( 1 case) metastatic squamous cell carcinoma was seen in cytology specimen $4.16 \%$ and was correlated with biopsy findings $4.16 \%$.

H Stokes-Lampard S Wilson C Waddell A Ryan R Holder S Kehoe Volume113, Issue12 December 2006 Pages 1354-1365

Subsequent to benign indications $(n=6543)$, $1.8 \%$ (117) of women had an abnormal smear, $0.12 \%$ (eight) had an abnormal biopsy and no cancers were identified.

Subsequent to CIN I or II: $3.1 \%$ had an abnormal vault smear, $1.3 \%$ an abnormal biopsy and no cancers were detected.

Subsequent to CIN III, $14.1 \%$ of women had an abnormal smear, $1.7 \%$ an abnormal biopsy and one vaginal cancer $(0.03 \%)$ was detected.

\section{DISCUSSION}

VAIN and vaginal cancers are rare diseases with unclear epidemiologies. Primary vaginal cancer is uncommon. Siegel et al. [9] later reported that primary vaginal cancer contributed to $3 \%$ of malignant neoplasms of the female genital tract. Vaginal cancer is not a common gynecological cancer. Some report rising trends especially in women beyond 75years of age [10]. Conclusive evidence has demonstrated that a large number of cervical cancers occur due to infection with HPV [7]. Brinton et al. found that low education, low income, previous abnormal Pap smears, genital warts and a history of hysterectomy were important risk factors for VAIN and vaginal cancer; other risk factors included a current or past history of CIN, immunosuppression, previous radiotherapy and exposure to diethylstilbestrol. Total hysterectomy involves the removal of the cervix and the uterus and closure of the top of the vaginal canal, creating a vaginal vault. Removal of the cervix eliminates the risk of developing a cervical cancer and the need for cervical cytology. Indications for hysterectomy include dysfunctional uterine bleeding; uterine pain, bleeding, and enlargement; uterine descensus and prolapse; uterine leiomyomas; septic abortions; and obstetric catastrophs. Other indications include pelvic inflammatory disease, pelvic endometriosis, ectopic pregnancy and cervical intraepithelial carcinoma (carcinoma in situ), early invasive cervical cancer, endometrial adenocarcinoma and sarcoma, trophoblastic disease, ovarian and fallopian tube neoplasms, and malignant disease of other adjacent organs. Benign indications account for more than $90 \%$ of hysterectomies $[3,4]$. Collating data from more than 6000 women, Stokes-Lampard et al reported that subsequent to hysterectomy for benign indications, 1.8 percent of women had an abnormal vaginal vault smear, 0.12 per cent had an abnormal biopsy and no cancers were identified [4]. Hysterectomy for CIN is a known risk factor for the subsequent development of VAIN, with reported rates ranging from 0.9 to 6.8 percent [11]. Our data suggested that the cytobrush is a more 
efficient sampling device than the traditional Ayre's spatula to collect sample from vaginal vault. However, the vaginal vault cytology is considered as an important screening procedure, the efficacy is low for the early detection of recurrent atypical or malignant vaginal lesions in post-hysterectomy patients $[3,4]$. There is risk of getting artifacts secondary to inflammation or by previous chemotherapy, radiotherapy, or surgery. The amount of exfoliated cells collected is generally low because of atrophy. In addition, the vaginal vault corners can be so narrow that the commonly used Ayres spatula is often unable to penetrate deeply into them [5]. The cytobrush device carries also the advantage of a deeper sampling by reaching the narrow corners sometimes produced by surgical interventions in the vaginal vault [5]. However, cytology of the vaginal vault can enable screening for pre-invasive disease of the vagina such as vaginal intraepithelial neoplasia (VAIN) or recurrence of previously treated cervical or vaginal cancer. High-grade cervical intraepithelial neoplasia (CIN), prior to or at the time of total hysterectomy, is a known risk factor for the development of secondary VAIN, with reported recurrence rates of $0.9-7.4 \%$ [11]. Based on an analysis of data from long-term follow-up studies conducted in women treated for high-grade CIN, Soutter et al. found that, in the context of cytology follow-up after hysterectomy, the rate of invasive disease remained elevated in comparison with the rate in the general population, until at least 20 years after treatment [12]. Soutter et al. performed a meta-analysis of 26 cohorts who had received treatment for CIN, including four cohorts who received hysterectomy treatment. They found that there was no significant difference in the incidence of invasive recurrence between those series in which women were treated with a total hysterectomy and those in which one of the conservative methods of treatment (ablation or excision) was used. The authors concluded that follow-up for women after hysterectomy for CIN should be the same as for women treated conservatively [12]. Pre-renewal National Cervical Screening Program (NCSP) guidelines recommended that women undergoing hysterectomy for high-grade CIN should be advised to continue annual cytologic surveillance, and noted the need for further investigation of the role of human papillomavirus (HPV) testing for this group. The proportion of hysterectomies performed for cancer or precancerous lesions has been reported to range from 6 to $10 \%$ [4]. Hysterectomy with concomitant cervical intraepithelialneoplasia (CIN), is often considered a definitive treatment for CIN, but development of subsequent vaginal intraepithelial neoplasia (VAIN) is known to range from $0.9 \%$ to $6.8 \%$ [1].

The Papanicolaou (Pap) smear, originally collected directly from the vagina, is the most effective test for detection of carcinoma of the vagina. Generally, routine vaginal smears are performed only for women who have been exposed in utero to diethylstilbestrol
(DES) and for women who have had a hysterectomy for cervical neoplasia $[13,14]$. The Papanicolaou smear has been widely used to screen for carcinoma of the cervix for over 40 years. Based on aggregated data from studies identified by a systematic review of the literature, Stokes-Lampard et al reported that $1.8 \%$ of women who had had a hysterectomy for a benign indication had an abnormal smear and no cancers were detected [4].

Vaginal vault resection is an effective treatment for vaginal recurrence of cervical cancer after hysterectomy and radiotherapy [15]. VAIN is 150 times less common than cervical intraepithelial neoplasia (CIN), and vaginal cancer is one of the rarest gynecological malignancies $(0.7$ per 100,000 women in UK [14]. The value of the vaginal vault smear test as a screening tool after hysterectomy for reasons other than cancer is not supported by the existing literature [17]. Recognized risk factors for VAIN include: CIN, immunosuppression, genital warts/human papilloma virus infection, radiation therapy and smoking [16]. Besides VAIN, the only group of women appearing to be at increased risk of primary vaginal cancer are those whose mothers took diethylstilbestrol during pregnancy [16]. Metastatic cancer in vagina is common and $80 \%$ to $98 \%$ of all cases with cancer in vagina are metastatic. In the majority primary cancer is either in the endometrium, cervix, vulva, ovary, breast, rectum, or kidney [9]. Hellman et al. [17] have reported that vaginal cancer can occur at any age. Squamous cell cancer of the vagina mostly occurs in older women, only $15 \%$ cases are in women younger than 40 . Almost $50 \%$ cases occur in women of 70 years or older [17]. Vaginal cancer is only 1 to 3 percent of gynecological cancers. Recently ACS reported that only about 1 of every 100 cancers of the female reproductive system is vaginal cancers [18].

\section{CONCLUSION}

In our study there is slight increase in percentage of recurrent lesions in post hysterectomy patients secondary to CIN 11 and CIN III and secondary to squamous cell carcinoma, compared to Stokes Lampard study. In conclusion, our data revealed that, there is good correlation between cytological and histopathological findings due to the availability of trained technicians and experienced pathologists in giving accurate reports. Our data revealed that in women with previous history of gynecological cancers, vaginal vault cytology is helpful in the detection of primary, and early detection of recurrent atypical and malignant lesions in post hysterectomy patients. Early detection along with timely and appropriate treatment will prolong patient survival rates and can prevent distant metastasis.

\section{ABBREVIATIONS}

CIN- Cervical Intraepithelial Neoplasia

VAIN- Vaginal Intraepithelial Neoplasia 
HPV- Human Papilloma Virus

$\mathrm{H} \&$ E- Hematoxylin and Eosin

\section{REFERENCES}

1. Schockaert, S., Poppe, W., Arbyn, M., Verguts, T., \& Verguts, J. (2008). Incidence of vaginal intraepithelial neoplasia after hysterectomy for cervical intraepithelial neoplasia: a retrospective study. American journal of obstetrics and gynecology, 199(2), 113-e1.

2. Lundholm, C., Forsgren, C., Johansson, A. L., Cnattingius, S., \& Altman, D. (2009). Hysterectomy on benign indications in Sweden 1987-2003: a nationwide trend analysis. Acta obstetricia et gynecologica Scandinavica,88(1), 52-58.

3. Wu, J. M., Wechter, M. E., Geller, E. J., Nguyen, T. V., \& Visco, A. G. (2007). Hysterectomy rates in the United States, 2003. Obstetrics \& Gynecology, 110(5), 1091-1095.

4. Stokes-Lampard, H., Wilson, S., Waddell, C., Ryan, A., Holder, R., \& Kehoe, S. (2006). Systematic review: Vaginal vault smears after hysterectomy for reasons other than malignancy: a systematic review of the literature. BJOG: $A n$ International Journal of Obstetrics \& Gynaecology, 113(12), 1354-1365.

5. Kalogirou, D., Antoniou, G., Karakitsos, P., Botsis, D., Papadimitriou, A., \& Giannikos, L. (1997). Vaginal intraepithelial neoplasia (VAIN) following hysterectomy in patients treated for carcinoma in situ of the cervix. European journal of gynaecological oncology, 18(3), 188-191.

6. Kalliala, I., Anttila, A., Pukkala, E., \& Nieminen, P. (2005). Risk of cervical and other cancers after treatment of cervical intraepithelial neoplasia: retrospective cohort study. Bmj, 331(7526), 11831185.

7. Lino, D., Vincenzo, C., Diego, S., \& Elio, C. (2012). What sampling device is the most appropriate for vaginal vault cytology in gynaecological cancer follow up? Radiology and oncology, 46(2), 166-169.

8. Vessey, M. P., VILLARD-MACKINTOSH, L. A. U. R. E. N. C. E., MCPHERSON, K., COULTER, A., \& YEATES, D. (1992). The epidemiology of hysterectomy: findings in a large cohort study. BJOG: An International Journal of Obstetrics \& Gynaecology, 99(5), 402-407.
9. Siegel, R. L., Miller, K. D., \& Jemal, A. (2016). Cancer statistics, 2016. CA: a cancer journal for clinicians, 66(1), 7-30.

10. Daling, J. R., Madeleine, M. M., Schwartz, S. M., Shera, K. A., Carter, J. J., McKnight, B., ... \& Tamimi, H. (2002). A population-based study of squamous cell vaginal cancer: HPV and cofactors. Gynecologic oncology, 84(2), 263-270.

11. Brinton, L. A., Nasca, P. C., Mallin, K., Schairer, C., Rosenthal, J., Rothenberg, R., ... \& Richart, R. M. (1990). Case-control study of in situ and invasive carcinoma of the vagina. Gynecologic oncology, 38(1), 49-54.

12. Soutter, W. P., Sasieni, P., \& Panoskaltsis, T. (2006). Long-term risk of invasive cervical cancer after treatment of squamous cervical intraepithelial neoplasia. International journal of cancer, 118(8), 2048-2055.

13. Abe, A., Matoda, M., Okamoto, S., Kondo, E., Kato, K., Omatsu, K., ... \& Takeshima, N. (2015). Resection of the vaginal vault for vaginal recurrence of cervical cancer after hysterectomy and brachytherapy. World journal of surgical oncology, 13(1), 137.

14. Dodge, J. A., Eltabbakh, G. H., Mount, S. L., Walker, R. P., \& Morgan, A. (2001). Clinical features and risk of recurrence among patients with vaginal intraepithelial neoplasia. Gynecologic oncology, 83(2), 363-369.

15. Deshpande, A. (2016). Vaginal Cancer Trends in Women of Low Resources Settings. Journal of Universal Surgery, 4(3), 54.

16. Dickinson, L., Mussey, M. E., Soule, E. H., \& Kurland, L. T. (1972). Evaluation of the effectiveness of cytologic screening for cervical cancer. I. Incidence and mortality trends in relation to screening. In Mayo Clinic Proceedings (Vol. 47, No. 8, pp. 534-44).

17. Hellman, K., Lundell, M., Silfverswärd, C., Nilsson, B., Hellström, A. C., \& Frankendal, B. (2006). Clinical and histopathologic factors related to prognosis in primary squamous cell carcinoma of the vagina. International Journal of Gynecologic Cancer, 16(3).

18. DeVita, V. T., Lawrence, T. S., \& Rosenberg, S. A. (2012). Cancer: principles \& practice of oncology: primer of the molecular biology of cancer. Lippincott Williams \& Wilkins. 